\title{
Exploring Occupational and Familial Risks for Chronic Myeloid Leukaemia
}

\author{
Nicholas Anthony Othieno-Abinya ${ }^{1}$, Walter Otieno Mwanda $^{2}$, Joseph David Macharia Maina ${ }^{3}$, Andrew \\ Odhiambo $^{1}$, Peter Oyiro ${ }^{1}$, Sitna Ali Mwanzi ${ }^{4}$, Esther Musyoka Dindi ${ }^{1}$ and Anne Waweru ${ }^{3}$ \\ 1. Department of Clinical Medicine and Therapeutics, Section of Haematology/Oncology, University of Nairobi, Nairobi 00202, \\ Kenya \\ 2. Department of Human Pathology, Section of Haematology and Blood Transfusion, University of Nairobi, Nairobi 00202, Kenya \\ 3. Department of Medicine, Kenyatta National Hospital, Nairobi 00202, Kenya \\ 4. Department of Medicine, Section of Medical Oncology, AgaKhan University Hospital, Nairobi 00202, Kenya
}

\begin{abstract}
BACKGROUND: The malignant process in chronic myeloid leukaemia (CML) is driven by the BCR-ABL fusion gene encoding the p210 kd tyrosine kinase involved in downstream signaling activities resulting in leukaemia. The finding of BCR-ABL fusion in some normal, healthy individuals however confounds the picture, though activation of other downstream signaling pathways is required for proliferation of BCR-ABL-positive cells. Apart perhaps from exposure to atomic weapon or nuclear accident radiation, causes of BCR-ABL fusion are not well understood, making a case for more research. In this study, we intended to show association between patients' occupations, and also personal and family history of cancer, with occurrence of CML. METHODS: Patients with CML followed up at the Glivec International Patient Assistance Program (GIPAP) Clinic at the Nairobi Hospital had details of their occupations, personal and family histories of cancer taken. The latter included details of degree of relationship, and cancer type. RESULTS: Three hundred and ninety-eight patients were included. Males were $222(55.8 \%)$ and females 176 (44.2\%). Age range was 8-80 years, with a median of median of 44 years. Three hundred and fifty occupations were recorded. Farmers were the leading group, with $69(19.7 \%)$, followed by carpenters/builders/painters/masons/drivers 55 (15.7\%). Of note was a 32 year old man whose two female work mates in a telecommunications firm in the same building in Nairobi had acute myeloid leukaemia. Two hundred and sixty-seven (267) patients had personal or family history of cancer verifiable. Of these, 41 (15.4\%) gave positive history. Eight (3\%) were oesophageal cancer ( 5 among first degree relatives, 1 second degree, 2 third-degree). Eight (3\%) were prostate cancer (4 first-degree, 1 second degree, 3 third degree). Five (1.9\%) were breast cancer ( 1 self, 1 first degree, 3 second degree). CONCLUSION: Occupational profiles shown mirror the frequencies of cancers as seen in the general population. The three workmates who developed myeloid leukaemias cannot be ignored as they raise serious occupational concerns. Familial associations with other cancers could be epidemiological, implying, purely by chance.
\end{abstract}

Key words: Chronic myeloid leukaemia, BCR-ABL fusion, predispositions, ionizing radiation, occupational history, family history.

\section{Introduction}

Chronic myeloid leukaemia (CML) is one of the myeloproliferative neoplasms (MPNs). A significant proportion of these neoplasms, especially CML evolve terminally into acute myeloid leukaemia (AML). The major distinction between CML and the other MPNs is the possession of Philadelphia chromosome by the

Corresponding author: Nicholas Anthony Othieno-Abinya, FRCP-professor, research fields: malignant haematology and breast cancer. malignant leukaemia cells in CML [1]. This chromosome results from reciprocal translocation between the long arm of chromosome 9 at band q34 and the long arm of chromosome 22 at band q11: $t(9 ; 22)(q 34 ; q 11)$. This exchange of chromosome material brings together the Abelson (ABL) gene on chromosome 9 and the Breakpoint cluster region (BCR) gene on chromosome 22 , resulting in the $\mathrm{BCR}-\mathrm{ABL}$ fusion gene [2, 3]. The malignant process in CML is driven by this gene which encodes the p210 kilodalton (kd) tyrosine kinase, involved in downstream signaling 
activities culminating in leukaemia. The finding of BCR-ABL fusion in some normal, healthy individuals however confounds the pathogenetic events underlying CML development. However, activation of downstream signaling pathways including PI3K/Akt/MTOR, RAS/MER/ERK, Hedgehog, are required for proliferation of BCR-ABL-positive cells [4]. Apart perhaps from exposure to atomic weapon and/or nuclear accident irradiation [5, 6] carcinogenic events causing BCR-ABL fusion are not understood, necessitating further studies.

In an earlier case control study, we found no clear environmental or occupational factors associated with occurrence of CML [7]. In the current study, we carried out further interrogation of occupations of CML patients to try and recognize any occupational risk factors. We also interrogated self or family histories of other cancers just in case of rare familial associations which could be explained through common genetic pathways with or without epigenetic interplay.

\section{Methods}

Patients with CML followed up at the Nairobi Hospital's Glivec International Patients' Assistance Program (GIPAP) Clinic were studied. This clinic takes care of patients from all over Kenya and others from the region. In a retrospective evaluation of data deliberately collected prospectively, details were taken of their dates of diagnosis, occupations, and also personal and family history of cancer. If there was history of cancer, cancer type and degree of relationship were recorded as self, first degree, second degree, third or fourth degree.

Data was extracted from questionnaires and entered into an SPSS (version 21) spreadsheet. Descriptive statistics, including means and standard deviations, were computed and presented in tables. The Independents Samples T-test was used to determine the differences in occurrence of cancer by age, and multinomial regression to determine the relationship between the occurrence of various cancer types and the familial history of cancer of patients.

\section{Results}

Three hundred and ninety-eight (398) patients enrolled between November 2005 and April 2015 inclusive were included. Males were 225 (55.8\%) and females $176(44.2 \%)$. Age range was 8-80 years, with a median of 44 years. Three hundred and fifty occupations were recorded. Farmers were 69 (19.7\%), carpenters/builders/painters/masons/drivers $\quad 55$ $(15.7 \%)$, students $44(12.6 \%)$, teachers $30(8.6 \%)$, housewives 30 (8.6\%), businessmen/women 26 (7.4\%), casual labourers $24(6.9 \%)$, pastors/administrators 23 (6.6\%), college graduates and those in high-income brackets $16(4.6 \%)$, secretarial/clerical workers 15 (4.3\%), the unemployed 8 (2.3\%), nurses/social workers $10(2.9 \%)$ (Table 1).

Of note was that of a 33-year old male, a systems analyst working for a mobile phone company in Nairobi, and had a diagnosis of CML on 04/03/2015. A female aged 40 years, who worked for the same firm and occupied the same floor had been diagnosed with AML in October 2006, and another female who worked for the same firm in the same office as the latter, was also diagnosed with AML in 2011. Both women carried out secretarial duties.

Two hundred and sixty-seven (267) patients had personal or family history of cancer verifiable. Fourty-one (15.4\%) gave positive history. Of these 8 (3\%) were oesophageal cancer (5 among first degree relatives, 1 second degree, 2 third-degree). Eight (3\%) were prostate cancer (4 first-degree, 1 second degree, 3 third degree). Five (1.9\%) were breast cancer (1 self, 1 first degree, 3 second degree). Others were $4(1.5 \%)$ myeloid leukaemia, $3(1.1 \%)$ uterine cervix, $2(0.7 \%)$ lung, $2(0.7 \%)$ colon, $2(0.7 \%)$ nasopharynx. Stomach, uterine body, melanoma, non-melanoma skin, each had $1(0.4 \%)$. Two had poorly defined primaries (Table 2 ). 
Table 1 Gender and occupation.

\begin{tabular}{lllll}
\hline & \multicolumn{3}{c}{ Gender } \\
\cline { 2 - 5 } Occupation & Male & Female & Total & $\%(n=350)$ \\
\hline Professional & 14 & 2 & 16 & 4.6 \\
Farmer & 34 & 35 & 69 & 19.7 \\
Housewife & - & 30 & 30 & 8.6 \\
Teachers \& administrators & 37 & 16 & 53 & 15.1 \\
Unemployed & 5 & 3 & 8 & 2.3 \\
Business & 8 & 18 & 26 & 7.4 \\
Student & 28 & 16 & 44 & 12.6 \\
Casuals & 16 & 8 & 24 & 6.9 \\
Clerical/secretarial & 6 & 9 & 15 & 4.3 \\
Nursing/social work & 6 & 4 & 55 & 2.9 \\
Carpenter/builder/mason/technician & 50 & 5 & 350 & 15.7 \\
Total & 238 & 180 & 68 & 100 \\
Unknown & 34 & 34 & &
\end{tabular}

Table 2 Family history of cancer $(n=267)$.

\begin{tabular}{|c|c|c|c|c|c|c|c|}
\hline \multirow[b]{2}{*}{ Cancer Type } & \multicolumn{5}{|c|}{ Familial History of Cancer $(n=267)$} & \multirow[b]{2}{*}{ Wald $X^{2}$} & \multirow[b]{2}{*}{$P$ value } \\
\hline & Self & First & Second & Third & Fourth & & \\
\hline Oesophagus & 0 & 5 & 1 & 2 & 0 & 2.79 & 0.25 \\
\hline Prostate & 0 & 4 & 1 & 3 & 0 & 1.54 & 0.47 \\
\hline Breast & 1 & 1 & 3 & 0 & 0 & 1.45 & 0.48 \\
\hline Myeloid Leukaemia & 0 & 1 & 1 & 1 & 1 & 0.00 & 1.00 \\
\hline Uterine/cervix & 0 & 2 & 0 & 1 & 0 & 0.32 & 0.57 \\
\hline Neural PoVs & 0 & 2 & 0 & 0 & 0 & & \\
\hline Lung & 0 & 2 & 0 & 0 & 0 & & \\
\hline Colon & 0 & 1 & 1 & 0 & 0 & & \\
\hline Stomach & 0 & 1 & 0 & 0 & 0 & & \\
\hline Uterine/body & 0 & 0 & 1 & 0 & 0 & N/A & \\
\hline Ovary & 0 & 0 & 1 & 0 & 0 & & \\
\hline Melanoma & 0 & 1 & 0 & 0 & 0 & & \\
\hline Non-Melanoma & 0 & 0 & 1 & 0 & 0 & & \\
\hline Unknown & 0 & 1 & 1 & 0 & 0 & & \\
\hline
\end{tabular}

\section{Discussion}

Among Caucasians CML has a median age of occurrence at about 67 years, but in this cohort the median age was 44 years, similar to that seen in our earlier study [7], and another study in Nigeria [8].

Some of the best known carcinogens include ionizing radiation, chemicals and drugs; tobacco, and alcohol; infections, environmental pollutants, and genetic/hereditary factors. For myeloid leukaemias in general, ionizing radiation and drugs, including anticancer agents are better established as carcinogenic. For CML in particular, apart from advancing age and male sex, only nuclear bomb irradiation has been established as a cause [5, 6]. Most other associations such as exposure to benzene are largely weak $[7,9,10]$.

Studies have not shown clear association between chronic myeloid leukaemia and farming. However, a case control study in Iowa and Minnesota found pesticide exposure and other agricultural factors to be significant risks [11]. In this study, though the numbers were small, farming topped the list of occupations at $19.7 \%$, followed by those engaged in manual, outdoor jobs such as carpenters, builders, masons, painters, and drivers, at $15.7 \%$. The definition of a farmer though, can be vague in our environment, ranging from a 
peasant to a large scale commercial farmer. Farmers referred to here were mainly peasants.

Individuals in high-income brackets only constituted $4.6 \%$, as were those mainly engaged in indoor jobs such as secretaries, clerical workers, social workers and nurses at $4.3 \%$. There may perhaps be something protective about working indoors, or vice versa. Kabat and colleagues found that female sex and years of education were inversely associated with CML risk, while smoking intensity and high body mass were directly associated in a large study among patients aged 50-71 years [12]. Whereas the rich in low- and mid-income countries tend to be obese, smoking is not prohibited among them. It is therefore unclear why the rich were not well represented.

It is notable that three employees of the same firm, working in the same office, developed myeloid leukaemias. It could be purely by chance, but in a telecommunications, establishment the work environment cannot be ignored. Childhood leukaemia has been associated with exposure to residential electromagnetic fields [13-15]. These observations lead to adoption of underground new building power lines where possible to prevent the building of new residential buildings within 60 metres of existing power lines. Other studies have however failed to show any connection between high voltage power lines or mobile phones with leukaemia [16].

As for family history of cancer, there are no clear hereditary factors associated with CML. Identical twins of patients with CML are not at greater risk of developing CML than other siblings. This supports the role of environmental factors as being more relevant in CML development than hereditary factors. CML is not known to be related to any of the familial cancer syndromes.

We tried to explore other cancers that could through shared hereditary molecular susceptibility pathways be influenced by environmental factors, possibly epigenetically, to lead to CML. The correlations with cancers of the prostate, breast, oesophagus, and uterine cervix as seen here could be purely by chance, as it mainly mirrors the epidemiologic realities because these are the commonest cancers locally [17]. In any case, even though BCR-ABL fusion is the central oncogenic event in CML, activation of other downstream signaling pathways are required for leukaemic transformation of BCR-ABL positive cells [4]. Unifying downstream signaling pathways that could link these cancers genetically or even epigenetically include PI3K/AKT/RAF1/MEK1'2/ERK, or EGFR-stimulated RAS/RAF/MEK/ERK/PI3K/AKT. They should be interrogated further.

\section{Conclusion}

Occupational profiles shown mirror the frequencies of cancers as seen in the general population. The three workmates who developed myeloid leukaemias cannot be ignored as they raise serious occupational concerns. Familial associations with other cancers could be epidemiological, in other words, purely by chance.

\section{Acknowledgements}

Noel Victor Onyango for statistical analysis.

\section{References}

[1] Nowell, P., and Hungerford, D. 1960. "A Minute Chromosome in Chronic Granulocytic Leukaemia." Science 142: 1497.

[2] de Klein A., van Kessel, A. G., Grossveld, G., Bartram, C. R., Haqemeijer, A., Bootsma, D., Spurr, N. K., Heisterkamp, N., Groffen, J., and Stephenson, J. R. 1982. "A Cellular Oncogene Is Translocated to the Philadelphia Chromosome in Chronic Myeloid Leukaemia." Nature 300 (5894): 765-7.

[3] Deiniger, M. W., Goldman J. M., and Melo, J. V. 2000. "The Molecular Biology of Chronic Myeloid Leukaemia." Blood 96 (10): 3343-46.

[4] Skorski, T., Kanakaraj, P., Nieborowska-Skorska, M., Ratajczak, M. Z., Wen, S. C., Gewirtz, A. M., Perussia, B., and Calabretta, B. 1995. "Phosphatidylinositol-3 Kinase Activity Is Regulated by BC/-ABL and Is Required for the Growth of Philadelphia Chromosome-Positive Cells." Blood 86 (2): 726-36.

[5] Heyssel, R., Brill, B., Woodbury, L. A., Nishimura, E. T., Ghose, T., Hoshino, T., and Yamasaki, M. 1960. 
"Leukaemia in Hiroshima Atomic Bomb Survivors." Blood 15: 313-31.

[6] Kato, H., and Schull, W. J. 1982. "Studies of the Mortality of A-Bomb Survivors. 7. Mortality, 1950-1978: Part 1. Cancer Mortality." Radiat. Res. 90 (2): 395-432.

[7] Kasmani, R., Othieno-Abinya, N. A., Riyat Mt, S., Kiarie, G. W., and Wanzala, P. 2014. "Environmental and Occupational Factors Associated with Chronic Myeloid Leukaemia: A Case-Control Study.” J. Afr. Cancer 6 (4): 194-201.

[8] Mamman, A., Yusuf, A., Amin S., Sheikh, T. L., and Hassan, A. 2009. "Severe Depression Following $\alpha$-Interferon Usage in a Patient with Chronic Myeloid Leukaemia.” Africa Health Sci. 9 (1): 54-6.

[9] Dean, M. R. 1996. "Chronic Myeloid Leukaemia and Occupational Exposure to Benzene in a Royal Navy Submariner." JR Nav. Med. Serv. 82 (1): 28-33.

[10] Saberi, H. F., Christopher, Y., Peeters, P., Romieu, I., Yun, W., Riboli, E., Raaschou-Nielsen, O., Tionneland, A., Becker, N., Nieters, A., Trichopolou, A., Bamia, C., Orfanos, P., Oddone, E., Lujan-Barroso, M., Navarro, C., Barricarte, A., Molinna-Montes, E., Wareham, N., Vinesi, P., and Vermeulen, R. 2013. "Occupation and Risk of Lymphoid and Myeloid Leukaemias in the European Prospective Investigation into Cancer and Nutrition (EPIC)." Occup. Environ. Med. 70 (7): 464-70.

[11] Brown, L. M., Blair, A., George, D., Everett, G. D., Cantor, K. P., Schuman, L. M., Burmeister, L. F., van Lier, S. F., and Dick, F. 1990. "Pesticide Exposure and Other Agricultural Risk Factors for Leukaemia among Men in Iowa and Minnesota." Cancer Res. 50 (20): 6585-91.

[12] Kabat, G. C., Wu, J.W., Moore, S. C., Morton, L. M., Park, Y., Hollenbeck, A. R., and Rohan, T. E. 2013. "Lifestyle and Dietary Factors in Relation to Risk of Chronic Myeloid Leukaemia in the NHH-AARP Diet and Health Study." Cancer Epidemiol. Biomarkers Prev. 22 (5): 848-54.

[13] Schuz, J., and Ahlbom, A. 2008. "Exposure to Electromagnetic Fields and the Risk of Childhood Leukaemia: A Review." Radiat. Prot. Dosimetry 132 (3): 202-11.

[14] Draper G., Vincent T., Kroll, M. E., and Swanson, J. 2005. "Childhood Cancer in Relation to Distance from High Voltage Power Lines in England and Wales: A Case-Control Study.” BMJ 330 (7503): 1290-2.

[15] Versakalo, P. K., Pukkala, E., Hongisto, M. Y., Valjus, J. E., Jarvinen, P. J., Heikkila, K. V., and Koskenvuo, M. 1993. "Risk of Cancer in Finnish Children Living Close to Power Lines.” BMJ 307 (10): 895-9.

[16] Tynes, T., and Holdersen, T. 1997. "Electromagnetic Fields and Cancer in Children Residing Near Norwegian High-Voltage Power Lines.” Am. J. Epidemiol. 145 (20): 219-26.

[17] Korir, A., Okerosi, N., and Parkin, D. M. 2014. Nairobi Cancer Registry Report 2004-2008 Cancer Registry Report 2014. Cancer Incidence in Nairobi. Nairobi, Kenya. 